\title{
РОЛЬ ПРИВЕРЖЕННОСТИ ПАЦИЕНТОВ К ПОМПОВОЙ ИНСУЛИНОТЕРАПИИ ПРИ ДЛИТЕЛЬНОСТИ САХАРНОГО ДИАБЕТА 1 ТИПА БОЛЕЕ ТРЕХ ЛЕТ
}

\author{
И.М. Царгасова, О.А. Клиценко, О.С. Берсенева, Е.Б. Башнина, М.Е. Туркунова \\ ФГБОУ ВО «СЗГМУ им. И.И. Мечникова Минздрава России», г. Санкт-Петербург
}

АКТУАЛЬНОСТЬ: инсулиновые помпы широко используются при лечении сахарного диабета 1 типа (СД1) у детей из-за ряда преимуществ по сравнению с многократными ежедневными инъекциями инсулина (МИИ). Однако вопрос о долгосрочной эффективности непрерывной подкожной инфузии инсулина (НПИИ) в достижении и поддержании компенсации сахарного диабета все еще не решен.

ЦЕЛЬ: определить факторы, влияющие на эффективность гликемического контроля в группе детей и подростков с СД1 находящихся на НПИИ от 3 лет и более.

МЕтодЫ: исследованы данные 239 детей и подростков из Санкт-Петербурга, которые находились на помповой инсулинотерапии в течение 3 и более лет. Мы проанализировали динамику уровня $\mathrm{HbA}_{1 c}$ до постановки инсулиновой помпы и его последнего значения. Изменения НbA оценивались в зависимости от пола, возраста пациента, исходного уровня $\mathrm{HbA}_{1 c^{\prime}}$ а также таких факторов, как частота использования непрерывного подкожного измерения глюкозы (CGM в реальном времени), временные переходы от НПИИ к МИИ с помощью шприц-ручки, с использованием калькулятора болюса (КБ).

PЕзУЛЬтАТЫ: полученные данные последнего значения $\mathrm{HbA}_{1 c}$ не имели достоверно значи-

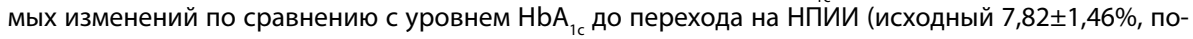

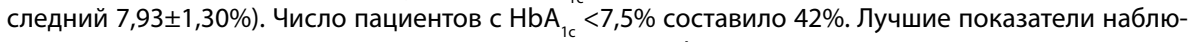
дались в группе 4,5-7 лет, где количество пациентов с $\mathrm{HbA}_{1 c}<7,5 \%$ составило 67\%; в группе 12-18 лет только $35 \%$ людей имели целевой $\mathrm{HbA}_{1 с}$. У большинства пациентов с исходным $\mathrm{HbA}_{1 c}<7,5 \%$ его последнее значение оставалось целевым, тогда как у пациентов с HbA $1 \mathrm{c} \geq 7,5 \%$ до перехода на НПИИ только $23 \%$ достигли целевого уровня. Также лучший гликемический контроль у пациентов, которые постоянно использовали НПИИ, по сравнению с пациентами, которые периодически переходили на МИИ с помощью шприц-ручки ( $<<0,05)$. $\mathrm{HbA}_{1 с}$ был ниже в группе подростков 12-18 лет, которые постоянно использовали НМГ в реальном времени, по сравнению с группой, которая не использовала НМГ $(p<0,05)$.

ЗАКЛЮЧЕНИЕ: статистически достоверного изменения уровня $\mathrm{HbA}_{1 с}$ У детей и подростков

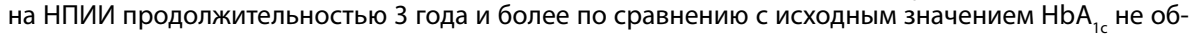
наружено. У большинства пациентов с целевым уровнем $\mathrm{HbA}_{1 c}(<7,5 \%)$ до перехода на НПИИ его последнее значение оставалось в пределах целевого диапазона, а у пациентов с исходным нецелевым уровнем $\mathrm{HbA}_{1 c}(\geq 7,5 \%$ ) только $23 \%$ достигли целевых значений, что может быть связано с недостаточным соблюдением методов лечения и самоконтроля.

КЛЮЧЕВЫЕ СЛОВА: сахарный диабет 1 mипа; инсулинотерапия; непрерывная подкожная инфузия инсулина; непрерывное мониторирование гликемии; гликированный гемоглобин. 